\title{
28 Research Soure \\ Temporary application of ox muzzle drainage in knee arthroscopic surgery
}

\section{Chunyu Zhang}

Fourth Affiliated Hospital of Harbin Medical University

Mochao Xiao

Fourth Affiliated Hospital of Harbin Medical University

Daifeng Lu ( $\sim$ ludaifengletter@163.com )

Fourth Affiliated Hospital of Harbin Medical University

\section{Technical note}

Keywords: ox muzzle drainage, arthroscopy, irrigation

Posted Date: April 13th, 2021

DOI: https://doi.org/10.21203/rs.3.rs-32770/v1

License: (c) (1) This work is licensed under a Creative Commons Attribution 4.0 International License.

Read Full License 


\section{Abstract}

Background: Ox muzzle drainage is temporary a type of drainage system surrounding the anterior internal and lateral incision of knee arthroscopy. In order to make the operation visual field clear, reduce the operation time, reduce the knee pain $\rrbracket$

Methods: A total of 104 patients with meniscal associated injury who underwent knee arthroscopic meniscus between May 2014 and June 2017 were retrospectively analyzed. Temporary use during surgery Ox muzzle drainage was applied in 51 patients, while the other 53 patients were served as conventional group. The volume of irrigation fluid drained from the knee articular cavity, duration of operation, operative view clarity and occurrence of anterior knee pain.Visual clarity was evaluated with a numerical rating scale.

Results: The irrigation fluid volume was significantly greater, while duration of operation was markedly

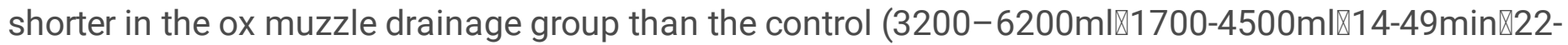
$63 \mathrm{~min} \otimes \mathrm{t}=11.494 \rrbracket \mathrm{t}=9.846 \rrbracket \mathrm{P}<0.01)$. The operative view clarity in the ox muzzle drainage group was obviously better than the control $(87.42 \% \varangle 66.09 \% \bigotimes t=5.474 \llbracket \mathrm{P}<0.05)$. The incidence of anterior knee pain was lower than that of the control group $\left(c^{2}=11.105 \bowtie P<0.01\right)$.

Conclusions: Ox muzzle drainage temporary is feasible for intra-operative irrigation and stretching of the fat pad in knee arthroscopy, It is conducive to the operation of surgical instruments, shortening the operation time, reducing the injury of the subpatellar fat pad and the occurrence of anterior knee pain.

\section{Introduction}

Suspension gravity irrigation was used in knee arthroscopic surgery Drainage of the irrigation solution is usually inadequate due to shielding by the capsula articularis and related soft tissue. Moreover, the operation equipment is difficult to fit in the joint cavity, and bulging of the fat pad into the knee joint cavity makes imaging unclear, resulting in extended operative times and difficulty in repairing lesions, which is especially troubling for inexperienced surgeons. Intra-articular bleeding has been proposed as the main cause of effusion after knee arthroscopy ${ }^{[1,2]}$. However, the application of tourniquet in lower limbs will lead to postoperative knee joint cavitation around the incision and postoperative venous thrombosis ${ }^{[3]}$. Therefore, tourniquet is rarely used in knee arthroscopic surgery at present. Do not apply a tourniquet During arthroscopy, the synovium and fat pad may need to be partially removed to visualize the anterior part of the menisci. ${ }^{[4,5]}$ However, the bleeding caused by excision of part of the synovium and fat pad results in knee joint effusion, anterior knee pain and affected surgical field of vision ${ }^{[4]}$. Therefore, sufficient outflow of lavage fluid in the knee joint cavity can make the field of vision clear without stasis in the joint cavity.Drainage is widely used in orthopedic interventions and will, theoretically, remove the initial hemarthrosisSome studies have reported that drains prevent effusions and painful irritation of the knee by reducing synovial irritation, It promotes fluid flow out of the joint ${ }^{[5,6]}$. 
Ox muzzle drainage was first applied in drainage of the focus of infection in osteomyelitis, and a good

curative effect was obtained. ${ }^{[7,8]}$ Can temporary use of this device in knee arthroscopic surgery promote the rapid elimination of lavage fluid, reduce fluid stasis in the joint cavity, and improve vision?0x muzzle drainage is temporary a type of drainage system surrounding the anterior internal and lateral incision of knee arthroscopy.In this study, the author investigated the application of a suspended gravity irrigation method to the temporary application of a bovine muzzle like drainage tube in the arthroscopic knee surgery for observation and analysis, and then removed the drainage device after the operation.

\section{Materials And Methods Patient information}

A total of 104 patients with a third-degree meniscus combined injury who underwent knee arthroscopic meniscus partial resection between May 2014 and June 2017 were retrospectively analyzed.Follow-up was conducted for 24 to 36 months, with an average of 30.6 months, The bovine muzzle drainage tube was temporarily applied to the patients with knee meniscus injury to reduce the error caused by different diseases. Subjects with contraindications for knee arthroscopy were excluded. The test group consisted of 51 patients in whom ox muzzle drainage was applied, and the control group consisted of 53 patients who underwent knee arthroscopy without ox muzzle drainage as routine drainage group. This study was approved by the ethics committee of the Fourth Affiliated Hospital of Harbin Medical University, and all enrolled patients provided written informed consent.

\section{Inclusion criteria}

$\triangle$ Knee joint meniscus tear arthroscopic surgery; $;$ the knee joint meniscus tear conservative treatment is invalid; $₫$ postoperative follow-up.

\section{Exclusion criteria}

\Patients with severe hypertension, diabetes, cardiovascular disease, or severe impairment of liver and kidney function; $₫$ Patients with knee joint disease, injury or surgical history unrelated to knee meniscus tear; \allergic or contraindicated to relevant drugs; \Mentally disabled.

\section{Operative method}

All patients were anesthetized with subarachnoid space block anesthesia,

For the patients in the ox muzzle drainage group, the infusion apparatus tube was cut to $20 \mathrm{~cm}$ in length. The knee joint was flexed at $90^{\circ}$, and a conventional lateral longitudinal incision of $1 \mathrm{~cm}$ in length was made. The large drainage tube was put into the knee articular cavity through the inner incision and inclined by about $45^{\circ}$, and the holding forceps were placed in the cavity from the lateral incision in closed status. Next, the drainage tube was held by the forceps and moved to the inner incision, causing the head 
of the forceps to extend out of the inner incision. Then the infusion tube was reflexed at $10 \mathrm{~cm}$, held by the forceps, and pulled from the lateral incision. A plier was used to extend the exterior and interior incisal opening of the articular capsule and for arthroscopy entry from the exterior side. Finally, the inner infusion tube was fit into the reflection end and placed under tension for the arthroscopic operation (Figs. 1A-D). For the patients in the control group, routine arthroscopy was performed. The volume of irrigation fluid drained from the knee articular cavity, the duration of operation, operative view clarity (categorized as clear or blurry), and complications were compared between the two groups. All the operations were performed by one surgeon using the same arthroscopy system (STORZ, Germany) and gravity perfusion system without tourniquet.Surgical clarity of vision was measured during arthroscopic knee surgery.The physician assessed the field sharpness score using the digital rating scale (NRS 0 to 10,10 for optimal visual sharpness).The relation of 4 is defined as "vague" when 4 \&lt;NRS \& It;7 is "general", when NRS $\& g t ; 7$ is "good".The cut-off value of the score is set at \&gt;7, because this is defined as a good intraoperative visibility ${ }^{[9]}[$

\section{Statistical analysis}

SAS9.3 software was used for data analysis. Measurement data are shown as mean \pm standard deviation, and significant differences were identified by $t$ test or rank sum test. Enumerated data were compared by chi-square test. $P<0.05$ was considered indicative of statistical significance.

\section{Results}

Overall, 51 patients underwent knee arthroscopy with ox muzzle drainage, including 35 men and 16 women with a mean age of $37.58 \pm 10.67$ years (range, 22-60 years). Among these cases, 17 involved left knees and 33 involved right knees, and 1 suffered required double knee arthroscopy. Another 53 patients who underwent knee arthroscopy without ox muzzle drainage were selected as controls, including 36 men and 17 women with an average age of $35.94 \pm 9.99$ years (range, 19-59 years). The cases in the control group included operations on 19 left knees and 32 right knees, and two cases of double knee arthroscopy.

As shown in Table 1, age, gender, and side did not differ significantly between the two groups $(P>0.05)$. The mean irrigation volume in the ox muzzle drainage group was ( $4786.27 \pm 648.08 \mathrm{ml}$ [range, 3200$6200 \mathrm{ml}])$, which was significantly greater than that in the control group (3158.49 $\pm 786.52 \mathrm{ml}[1700-$ $4500 \mathrm{ml}], \mathrm{t}=11.494, \mathrm{P}<0.01)$. Compared with the control operation, ox muzzle drainage provided an obviously clearer intra-operative view (Fig. 2). The median operation time in the ox muzzle drainage group was only $23.66 \pm 7.50 \mathrm{~min}$, which was significantly shorter than that in the control group (32.88 \pm $8.22 \mathrm{~min}, \mathrm{t}=9.846 \square \mathrm{P}<0.01$, Table 2 ). 
Table 1

General patient information

\begin{tabular}{|lllll|}
\hline & $\begin{array}{l}\text { Routine operation } \\
\text { group }\end{array}$ & $\begin{array}{l}\text { Ox muzzle drainage } \\
\text { group }\end{array}$ & $\mathrm{t} / \mathbf{\chi}^{2} / \mathbf{Z}$ & $\mathbf{P}$ \\
\hline Age (years) & 35.949 .99 & 37.5810 .67 & 0.63 & 0.5303 \\
\hline Gender (male/female) & $15 / 17$ & $15 / 16$ & 0.0144 & 0.9044 \\
\hline $\begin{array}{l}\text { Side } \\
\text { (right/left/bilateral) }\end{array}$ & $10 / 20 / 2$ & $13 / 17 / 1$ & 1.3710 & 0.6287 \\
\hline
\end{tabular}

Table 2

Operative time in the ox muzzle drainage group and control group

\begin{tabular}{|lllll|}
\hline & $\begin{array}{l}\text { Routine operation } \\
\text { group }\end{array}$ & $\begin{array}{l}\text { Ox muzzle drainage } \\
\text { group }\end{array}$ & $\mathrm{t} / \mathbf{\chi}^{2} / \mathbf{Z}$ & $\mathbf{P}$ \\
\hline Irrigation amount $(\mathrm{ml})$ & $3158.49 \pm 786.52$ & $4786.27 \pm 648.08$ & 11.494 & 0.000 \\
\hline Operation time $(\mathrm{min})$ & $32.88 \pm 8.22$ & $23.66 \pm 7.50$ & 9.846 & 0.000 \\
\hline $\begin{array}{l}\text { Incidence of anterior knee } \\
\text { pain }\end{array}$ & $49.01 \%(25)$ & $37.73 \%(20)$ & 11.105 & 0.001 \\
\hline
\end{tabular}

The proportion of visual clarity expressed as "good visibility" (NRS \&gt;7) operation time due to variable correction. Therefore, visual clarity is between $0 \%$ and $100 \%$.Interventions with significant primary effects with a clear view, This indicated that the bovine muzzle drainage group had a clearer visual field than the control group $(t=-5.474, P=0.009$, Table 3 ). The clarity of the operative view in the ox muzzle drainage group was obviously better than that in the control $\left(\chi^{2}=11.76, P=0.023\right.$, Table 3$)$. The incidence of anterior knee pain in the bovine nasolabial drainage group (37.73\%) was lower than that in the control group $(49.01 \%) \cdot\left(X^{2}=11.105, P=0.001\right)$

Table 3

Clarity of operative view in the ox muzzle drainage group and control group

\begin{tabular}{|llll|}
\hline & Cases & Clear & Blurriness \\
\hline Routine operation group & 32 & $23(71.87 \%)$ & $9(28.13 \%)$ \\
\hline Ox muzzle drainage group & 31 & $29(93.55 \%)$ & $2(6.45 \%)$ \\
$\chi^{2}=11.76, P<0.05$ & & & \\
\hline
\end{tabular}

\section{Discussion}

We aimed to determine whether ox muzzle drainage in knee arthroscopy offers a significant benefit in surgical time, irrigation volume, and Postoperative anterior knee pain compared to the normal procedure. 
The results of this study indicate that ox muzzle drainage with double traction does reduce the operative time and increase the amount of irrigation possible, while not changing the rate of operative complications Reduces subpatellar fat pad injury and anterior knee pain. This may be due to enhanced visualization due to the better drainage provided by the bovine muzzle drainage tube to reduce fluid turbulence and to reduce the incidence of anterior knee pain caused by the removal of the Infrapatellar Fat Pad (IFP). IFP is a dynamic structure, which is easily disturbed by surgery because of its obvious displacement during knee movement.Surgical injury of IFP is believed to be the cause of postoperative anterior knee pain. Repeated surgical instrument stimulation will damage IFP, and fibrosis, lymphocyte infiltration and vascular proliferation will aggravate the pain ${ }^{[10-11]}[$

Yanmis $L^{[12]}$ andKuo $C^{[13]}$ think thorough irrigation for joint capsule expansion and a guarantee of clear vision are necessary for the operation. Irrigation can remove the bleeding and debris, which is helpful for observing the interior joint cavity more clearly. At present, there are two methods for knee joint cavity irrigation: suspensory gravity irrigation and perfusion pressure pump irrigation. Suspensory gravity irrigation is a classic surgical method with advantages of lower equipment costs and simpler technology. However, the disadvantage is that the perfusion pressure is unstable. Low pressure can cause vision to be blurred by joint cavity hemorrhage, whereas high pressure can cause turbulence, which is bad for vision and increases the degree of edema after the operation. The perfusion pressure pump method offers the advantage of an adjustable pressure, which helps maintain clear vision and reduces the operative time. $[14,15]$ It can alleviate the degree of edema after operation by reducing the infiltration of liquid. Moreover, it can prevent the phenomenon of water interruption and air entering the joint cavity. However, the related equipment is associated with certain costs. On the other hand, the pressure difference of less than $50 \mathrm{mmHg}$ compared with the systolic pressure can reduce bleeding and improve the clarity of vision ${ }^{[16 \text {, }}$ 17], although it also may increase the risk of perfusion fluid extravasation and lead to osteofascial compartment syndrome ${ }^{[18]}$. Seig thought that the perfusion pump could shorten the operation time compared with suspensory irrigation. ${ }^{[19]}$ Contrarily, Tatari proposed that although use of drains can improve the vision, Suspensory irrigation cannot provide clear vision, because the drainage may be blocked by the subcutaneous tissue and joint capsule under the lateral edge of the incision.Thus, a drain tube is needed to discharge the irrigation fluid containing blood and debris, which further extends the operation time. ${ }^{[20,21]}$

Ox muzzle drainage permits sufficient drainage in multiple conditions such as osteomyelitis ${ }^{[22,}$ ${ }^{23]}$.Temporary application Ox muzzle drainage was associated with three advantages. First, it holds the subcutaneous tissue under the edge and prevents aggregation of the knee joint capsule cannot, which benefits clear vision. Secondly, the ox muzzle drainage tube can effectively pull open the fat pad to improve the surgical view, instead of cleaning the fat pad, thus shortening the operation time. Thirdly, the surgical instruments can be placed within the joint cavity to place the tube easily, avoiding unnecessary side injury to structures such as the articular cartilage, meniscus, and cruciate ligament. ${ }^{[24,25]}$ Lastly, it may avoid osteofascial compartment syndrome caused by fluid infiltration to the crural fascia upon 
osmotic pressure. ${ }^{[26,27]}$ Therefore, ox muzzle drainage is theoretically an ideal choice for knee arthroscopy.

Every 5 to 10 minutes, we looked at the quality of visibility (NRS) by the overall rating of the physician, to see if it could provide a better visualization,According to the method used by Tuijthof ${ }^{[28]}$ et al, visual clarity is measured and the ratio of "good visibility" is expressed (NRS \& gt;7).We found that the bovine muzzle drainage tube improved visual clarity.Turbidity is the most common source of disturbance in knee arthroscopy and is present during a considerable percentage of the operation time. Our results show that for routinely performed arthroscopic knee operations, the ox muzzle drainage system resulted in a significantly reduced presence of turbidity. This finding can be explained by the continuous flow that spanned a wider area due to the traction of the drainage tube, as opposed to the flow caused by leakage along the portals. Meanwhile, the larger amount of irrigation used in ox muzzle drainage group further supports this conclusion. In addition, the shorter operation time in the ox muzzle drainage group also prompted faster and easier insertion and removal of the surgical instruments.

Our study had some limitations. Our series was not large, because this is a new attempt in knee arthroscopy. Moreover, our follow-up time was short. Thus, a study with a larger population and longer follow-up is needed to better evaluate the effectiveness and convenience of ox muzzle drainage in knee arthroscopy. Furthermore, many experienced surgeons can still create a clear surgical view and shorten the operation time effectively without ox muzzle drainage. Therefore, in our opinion, ox muzzle drainage is most helpful for beginner surgeons performing knee arthroscopy.

\section{Conclusion}

Our investigation demonstrated that use of ox muzzle drainage in knee arthroscopy resulted in a clearer surgical view the traditional method not involving ox muzzle drainage. Thus, we believe that ox muzzle drainage is a feasible method for the drainage of intra-operative irrigation fluid and stretching of the fat pad in knee arthroscopy, and that this approach can effectively improve the field of vision and shorten the operation time for knee arthroscopy, This method can effectively protect the subpatellar fat pad and reduce the incidence of anterior knee pain,especially for beginner surgeons.

\section{References}

1. Liu YF, Hong CK, Hsu KL, Kuan FC, Chen Y, Yeh ML, Su WR.Intravenous Administration of Tranexamic Acid Significantly Improved Clarity of the Visual Field in Arthroscopic Shoulder Surgery. A Prospective, Double-Blind, and Randomized Controlled Trial.Arthrocopy.2020Mar;36(3):640-647.

2. DeMaio M. Giants of orthopaedic surgery: Masaki Watanabe MD. Clin Orthop Relat Res 2013;471:2443-8.

3. Oh JH, Kim JY, Chung SW et al .Warmed irrigation fluiddoes not decrease perioperative hypothermia during arthroscopicshoulder surgery. Arthroscopy2014 30(2):159-164 
4. Ma C, Cui X, Chen F, Ma L, Xin S, Liao H. Knee arthroscopic navigation using virtual-vision rendering and self-positioning technology. Int J Comput Assist Radiol Surg. 2020;15(3):467-477.

5. Vandit Sardana, Joanna Burzynski, Giles R. Scuderi.The influence of the irrigating solution on articular cartilage in arthroscopic surgery: A systematic review. Journal of Orthopaedics 2019; 16:158-165.

6. Milankov M, Savic D. The importance of irrigation suction drainage in the treatment of septic arthritis after anterior cruciate ligament reconstruction. Arthroscopy 2008;24:1434-5; author reply 5.

7. Green SA. Osteomyelitis. The llizarov perspective. Orthop Clin North Am 1991;22:515-21.

8. Harada K,McConnell I,DeRycke EC,Holleck JL,Gupta S.Native joint septic arthritis:comparison of outcomes with medical and surgical management.South Med J.2019 Apr;112(4):238-243.

9. Douwe O. van Montfoort, M.D., Paulien M. van Kampen, Ph.D., and Pol E. Huijsmans, M.D. Epinephrine Diluted Salineelrrigation Fluid in Arthroscopic Shoulder Surgery: A Significant Improvement of Clarity of Visual Field and Shortening of Total Operation Time. A Randomized Controlled Trial. Arthroscopy: The Journal of Arthroscopic and Related Surgery 2016;32(3):436-444.

10. Stephen JM, Sopher R, Tullie S, Amis AA, Ball S, Williams A. The infrapatellar fat pad is a dynamic and mobile structure, which deforms during knee motion, and has proximal extensions which wrap around the patella. Knee Surg Sports Traumatol Arthrosc. 2018;26(11):3515-3524.

11. Belluzzi E, Stocco E, Pozzuoli A, et al. Contribution of Infrapatellar Fat Pad and Synovial Membrane to Knee Osteoarthritis Pain. Biomed Res Int. 2019『2019:6390182.

12. Yanmis I, Ozkan H, Koca K, Kilincoglu V, Bek D, Tunay S. The relation between the arthroscopic findings and functional outcomes in patients with septic arthritis of the knee joint, treated with arthroscopic debridement and irrigation. Acta Orthop Traumatol Turc 2011;45:94-9.

13. Kuo CL, Chang JH, Wu CC, Shen PH, Wang CC, Lin LC, et al. Treatment of septic knee arthritis: comparison of arthroscopic debridement alone or combined with continuous closed irrigationsuction system. J Trauma 2011;71:454-9.

14. Avery DM 3rd, Gibson BW, Carolan GF. Surgeon-rated visualization in shoulder arthroscopy: A randomized blinded controlled trial comparing irrigation fluid with and without epinephrine. Arthroscopy 2015;31:12-18.

15. Mayo M, Wolsky R, Baldini T, Vezeridis PS, Bravman JT.Gravity Fluid Flow More Accurately Reflects Joint Fluid Pressure Compared With Commercial Peristaltic Pump Systems in a Cadaveric Model. 2018 Dec;34(12):3132-313.

16. Johnson LL. What I Have Seen and Learned Since Looking Through an Arthroscope: 43 Years and Counting. Arthroscopy 2015;31:1571-5.

17. Liang-Tseng Kuo, Chi-Lung Chen,Pei-An Yu, Wei-Hsiu Hsu,Ching-Chi Chi, Jae-Chul Yoo .Epinephrine in irrigation fluid for visual clarity in arthroscopic shoulder surgery: a systematic review and metaanalysis. International Orthopaedics;2018,6(22),424-428. 
18. Mayo M,Wolsky R,Baldini T,Vezeridis PS,Bravman JT.Gravity fluid flow more accurately reflects joint fluid pressure compared with commercial peristaltic pump systems in a cadaveric model.Arthroscopy.2018 Dec;34(12):3132-3138.

19. Sieg R, Bear R, Machen MS, Owens BD. Comparison of operative times between pressure and flowcontrol pump versus pressure-control pump for ACL reconstruction. Orthopedics 2009;32.

20. F. Stärke, F. Awiszus, C.H. Lohmann, C. Stärke. The effect of irrigation time and type of irrigation fluid on cartilage surface friction. Journal of the Mechanical Behavior of Biomedical Materials;2017,09008,124-129.

21. Tatari H, Dervisbey M, Muratli K, Ergor A. Report of experience in 190 patients with the use of closed suction drainage in arthroscopic knee procedures. Knee Surg Sports Traumatol Arthrosc 2005;13:458-62.

22. Hassan AS,Rao A,Manadan AM,Block JA,Joel A Block.Peripheral bacterial septic arthritis:review of diagnosis and management.J Clin Rheumatol.2017 Dec;23(8):435-442.

23. Thompson RM,Gourineni P.Arthroscopic treatment of septic arthritis in very young children.J Pediatr Orthop.2017 Jan;37(1):e53-e57.

24. Kocaoglu B, Martin J, Wolf B, Karahan M, Amendola A. The effect of irrigation solution at different temperatures on articular cartilage metabolism. Arthroscopy 2011;27:526-31.

25. Kosy JD, Schranz PJ, Toms AD, Eyres KS, Mandalia VI. The use of radiofrequency energy for arthroscopic chondroplasty in the knee. Arthroscopy 2011;27:695-703.

26. Friberger Pajalic K, Turkiewicz A, Englund M.Update on the Risks of Complications After Knee Arthroscopy.BMC Musculoskelet Disord. 2018 Jun;19(1):179.

27. Amin AK, Huntley JS, Patton JT, Brenkel IJ, Simpson AH, Hall AC. Hyperosmolarity protects chondrocytes from mechanical injury in human articular cartilage: an experimental report. J Bone Joint Surg Br 2011;93:277-84.

28. Avery DM 3rd, Gibson BW, Carolan GF. Surgeon-rated visualization in shoulder arthroscopy: A randomized blinded controlled trial comparing irrigation fluid with and without epinephrine. Arthroscopy 2015;31:12-18.

\section{Figures}


A

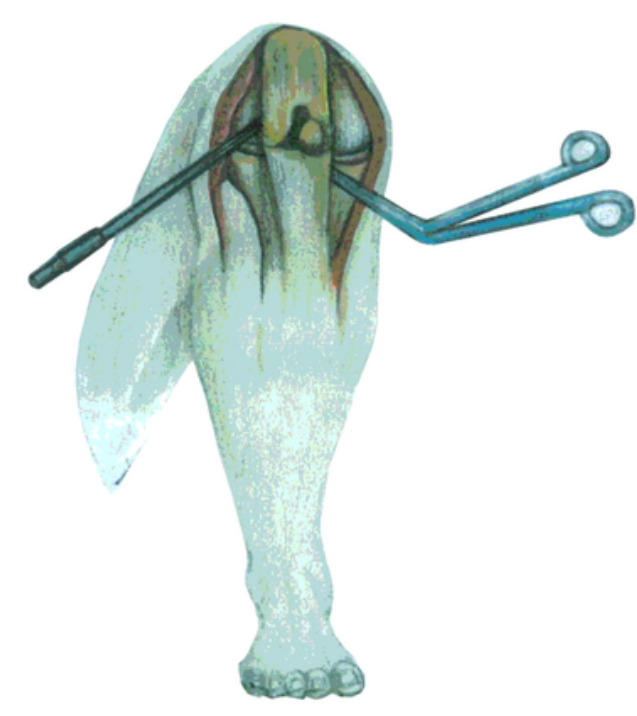

C

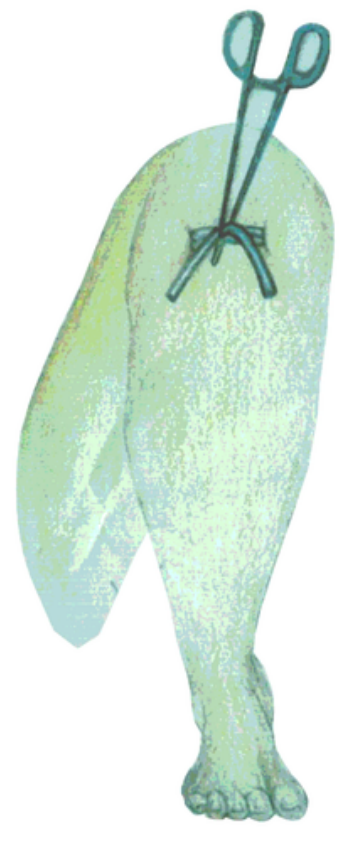

B

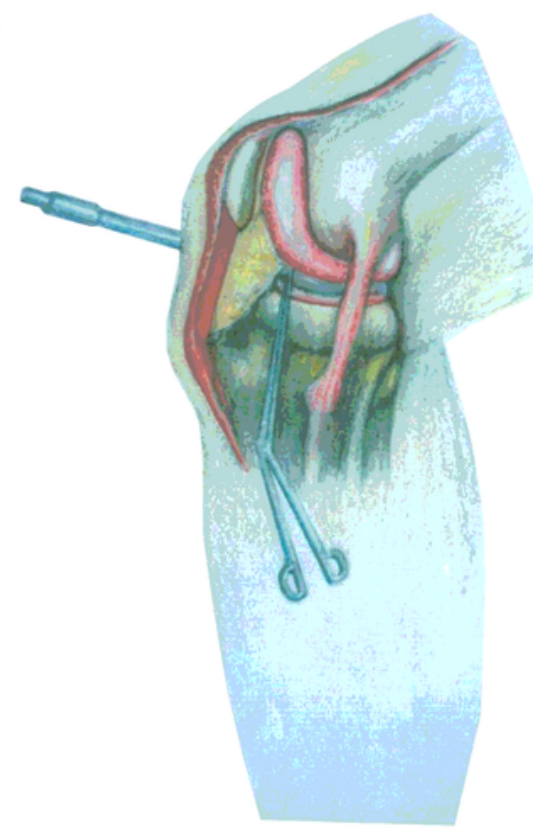

D

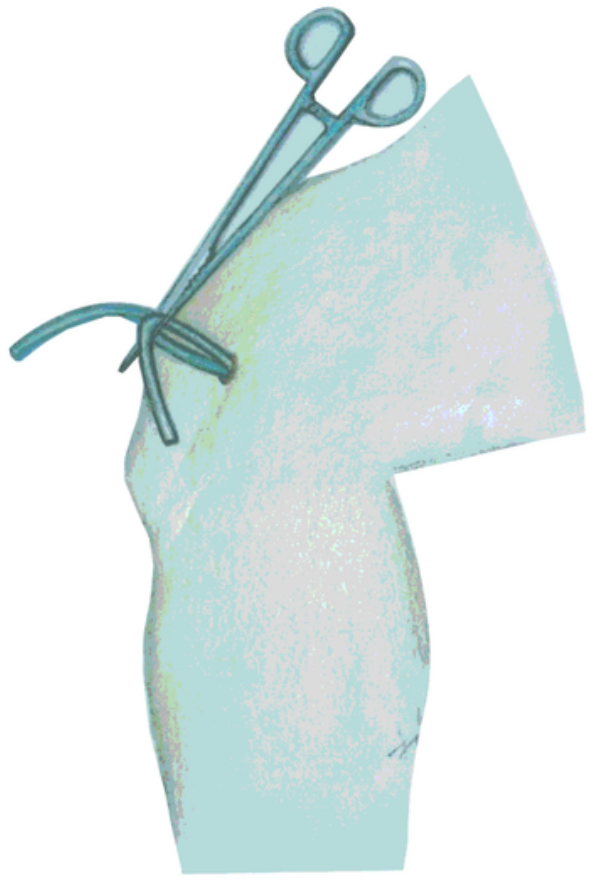

\section{Figure 1}

Operation process of ox muzzle drainage. (A) Anterior view of the knee joint showing the holding forceps and drainage tube head. (B) Lateral view of the knee joint showing the holding forceps and drainage tube head. (C) Anterior view of ox muzzle drainage after completion. (D) Lateral view of ox muzzle drainage after completion. 

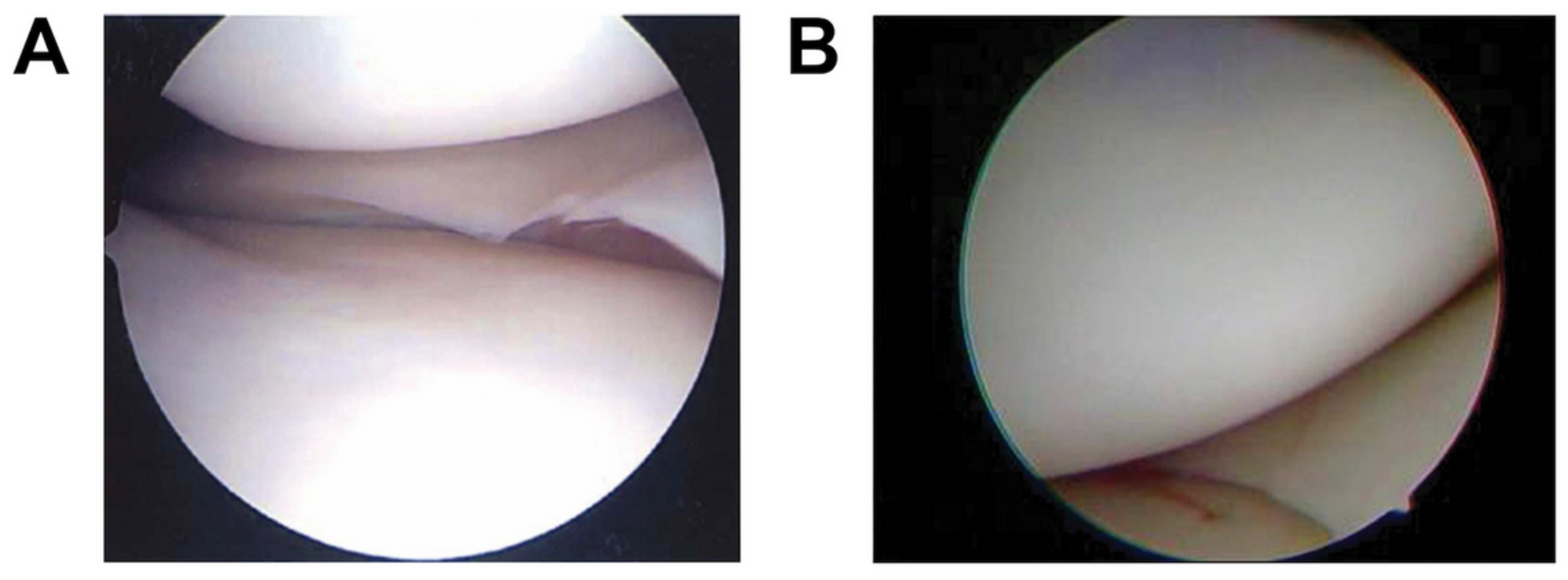

Figure 2

Intra-operative field of vision. (A) Ox muzzle drainage group. (B) Control group. 